tion of fatty acids, this incomplete oxidization resulting from $(a)$ the inability of the body to utilize carbohydrate adequateIy, or $(b)$ an insufficient supply of carbohydrates to enable the body to oxidize the fatty acids completely to their final products (Rübner and Zeller). In the former case the defect of metabolism is remedied by insulin, whilst the latter eventuality does not arise, owing to the high content of carbohydrate in the ration allowed.

2. The glycosuria can, in the average case, and in spite of the large amount of carbohydrate allowed, generally be abolished in a short time, any considerable "renal diabetic element" being compensated for as explained above.

3. The improvement in the gencral condition of the patient is considered, under this system, to be an even more important criterion of progress than a lowering of the blood sugar content, and is generally very noticeable; the first effect observed being usually a disappearance of the weakness and lassitude so characteristic of the diabetic. If the patient be weighed at the same time every morning the weight will nearly always be found to augment progressively; whilst the suppression of such symptoms as polyuria, polvphagia, and insomnia, together with the possibility of his leading a normally active life, generally has an important psychological as well as physical effect on the patient.

4. The blood sugar will always fall to a level approaching the normal, this being all that is considered absolutely necessary.

Of the remote effects of this treatment less can, naturally, be asserted, although the diabetic process appears in many cases to have been arrested for various periods-as, for example, in the case of the two patients mentioned above who were free from all symptoms for over a year, after several insulin "cures"; such cases, however, form a minority of the whole, the average free period being considerably shorter. Actually no case is allowed to go for more than about three months without receiving insulin, a new series being commenced automatically at the end of that period, whether any direct indication be present or not.

In certain cases, nearly always children, who have come under treatment late, it is found impossible to suspend the injections of insulin at all; these cases can, however, be brought to, and maintained in, a condition in which they can continue their normal lives and activities: The younger the patient the more necessary does it appear to start such a treatment early, and not to waste time on dietetic methods which seem, in most cases, to have little or no effect on the basal dietetic factor, but which merely suppress the symptom of glycosuria, and sometimes that of hyperglycaemia.

Finally, owing to the minimum of restrictions, both dietetic and otherwise, imposed on patients submitting to this regime, it is found to be easier to persuade them to continue on it over long periods than it would appear to be under some other methods of treatment.

1 Chabanier, Lobo-Onell, and REFERENCes

(liabite traites Press and Cire, Acad. de Med., March 24th, 1925. ¿Copeman, W. S. C.: Med. "Chabanier, H.: Du rôle du rein dans , 1925, and January 6th, 1926. Paris, 1925. "Chabanier, H.: Bull. de l'Acall. de Mid. (séance du 24 mars), 1925.

\section{A CASE OF PATENT DUCTUS aRTERIOSUS. BY}

WILLTAM GORDON, M.D., F.R.C.P., SENIOR PHYSICIAN TO THE ROYAL DEVON AND EXETER HOSPITAL.

THrs case, apart from its rarity, presents several features of interest.

A man, aged 31, a wine-merchant's cellarman since the war, a gymnasium instructor during the war, and a gardener before the war-all occupations involving heavy physical strain-has had gradually increasing shortness of breath for nine years, occasional short attacks of stabbing pain over the heart, mostly at" night, for six years, and palpitation caused rather by worry than by exertion. He has never had rheunatic fever, scarlet fever, or syphilis, never had a severe blow on the thorax, never felt anything "give way" in his ehest during an effort.

His heart is nearly normal in size, but a little dilated rightwards. The apex beat lies just inside the left mammary line-in the erect position it beats behind the sixth rib, but this is due to cardioptosis, since, in the recumbent posture, it is found, as normally, in the fifth space; but the right margin of its dullness in the erect position is $1 \frac{3}{4}$ inches to the right of the mid-linethat is, about an inch too far to the right. There is no excessive impulse anywhere and no thrill. In the second and third left intercostal spaces there can be made out, at least after exertion, Gerhardt's "ribbon dullness." 1 There is a loud, roaring, continuous murmur, lasting throughout the entire cardiac cycle, with tinuous murmur, lasting throughout the entire cardiac cycle, with marked systolio augmentation, loudest in the second left space by position. On recumbency the only noteworthy change in this murmur is a morement of its area of maximum loudness about $1 \frac{1}{2}$ inches leftwards. The murmur rapidly lessens in loudness as one recedes from this maximum area, except downwards along the left sternal border and the adjoining third, fourth, and fifth spaces. But it is faintly heard over almost the whole chest, heard over almost the whole chest,
front and back. In the area of front and back. In the area of audible second sound, but lower down, at the levels of the third, fourth, and fifth spaces, there is heard an accentuated and sometimes reduplicated second sound. Over the aortic cartilage and up the right carotid a clear second the right carotid a clear second
sound is audible, not reduplicated and nearly free from the continuous distant rumble of the murmur just described. At the sixth left space in the mammary line, in recumbency, the rumble is sometimes quite lost and then a second sound is clearly heard without reduplication or murmur. Fig. 1 shows most of murmur.

The pulse is regular, about 84 , rather sudden but not collapsing

and pulsation is certainly more visible than usual in the neck up than the right. lowest pressure of a Dudgeon's lowest pressure of a Dudgeon's sphygmograph; they do not suggest systolic and 55 diastolic The pulsus paradoxus, described by systolic and 55 diastolic The pulsus
François-Franck, ${ }^{8}$ is absent in this case.

$$
\text { Lelt }
$$

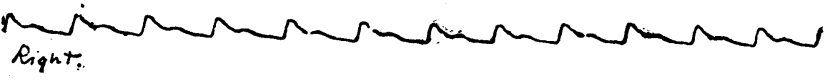

FIG. 2.

The respirations are quiet (20), the temperature constantly subnormal ( 1 had him six weeks in hospital), there is no enlargement of spleen or liver, no sign of embolism, no haemorrhage, no daily changes in the murmur. Except for pyorrhoea (which ho daily changes in the murmur. Except for pyorrhoea (which There is no clubbing of fingers, no polycythaemia, but after exertion there is slight cyanosis of the fingers.

\section{Diagnosis.}

The murmur is, as Gibson of Edinburgh ${ }^{2}$ first insisted, pathognomonic of patent ductus arteriosus-that is, a continuous murmur, with systolic augmentation, only dying out in the end of diastole; here $I$ do not lose it at any point of the cardiac cycle. It has received the names of the " tunnel murmur" and the "machinery murmur." It is quite different from any other murmur with which $I$ am acquainted. But it is said to be also produced by the opening of an aortic aneurysm into the pulmonary artery. The history of this case makes that diagnosis unlikely, and the $x$-ray examination definitely negatives it (Fig. 3).

Patent ductus arteriosus, then, accounts for the murmur. And in support of that diagnosis we find (1) the Gerhardt " ribbon dullness," (2) accentuated and divided second sound lower down, (3) unequal pulses (with, in this instance, low arterial tension, a feature not hitherto noted, I think, but likely to be common in this condition); some enlargement of the right heart, together with $x$-ray observation of dilatation and unusual pulsation of the pulmonary artery.

But it has been suggested that this might be a case of aortic regurgitation with an umusual dislocation of the murmur, because there is some visible pulsation in inhe neck. Apart from the facts that the murmur is absolutely different from any produced by aortic regurgitation and that such dislocation of an aortic murmur must be ex- 
tremely rare (except in case of transposition of the heart), this idea is negatived by the further facts that the aortic second sound is nearly free from rumble over the aortic cartilage and sometimes quite free from any murmurish sound below the apex in recumbency, whereas there is no second sound at all over the area of maximum murmur.

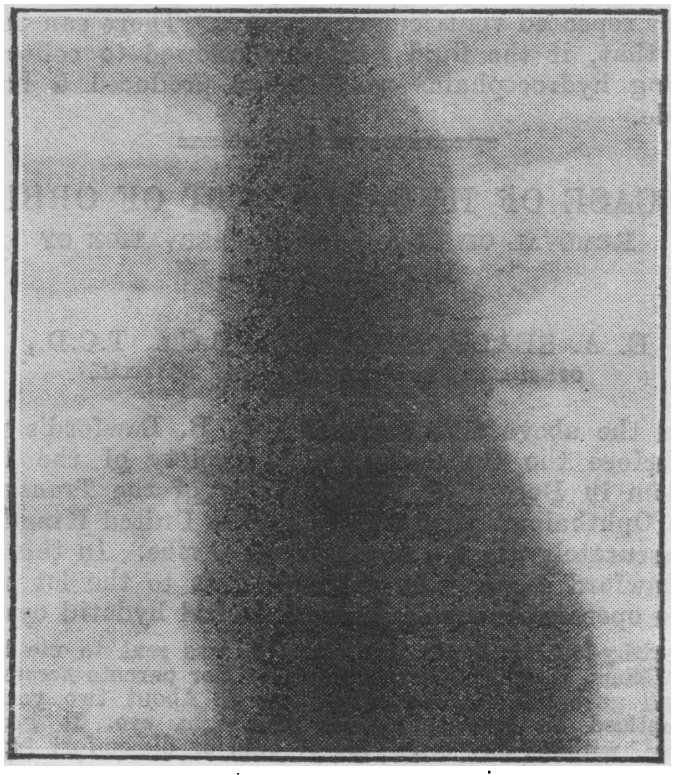

Fili. 3.

With regard to the visible pulsation in the arteries, $I$ do not know of any reference to it in other cases of this sort. Probably this is due to its usually slight degree. It should be remembered, however, that patent ductus arteriosus is itself a form of aortic leak $\rightarrow$ not, indeed, into the left rentricle, but into the pulmonary artery-and may, if free, be expected to produce a sufficient difference between the systolic and diastolic pressures to cause visible arterial pulsation. But these pressures would both be probably low as they are here, since the systolic pressure is not reinforced by the contraction of a powerful hrpertrophied left ventricle (as is the case in prdinary aortic regurgitation) and the leak is continuous through both sistole and diastole.

It may be asked how one can be sure that the divided second sound over the lower spaces is pulmonary. For a full exposition of the reasons I must refer to a previous paper. ${ }^{3}$ The current explanation of the dirision of the second pulmonary sound in mitral stenosis, or other diseases which increase the pressure in the pulmonary artery, can be easily disproved by mapping out its area of audibility and often by palpating the shock of the closure of the pulmonary cusps, which, like the sound, is reduplicated. The sound is produced by asynchronous closure of the pulmonary cusps themselves. This fact has a real ralue, as ill such a case as this, in distinguishing a second pulmonary from a second aortic sound, because, owing to its thicker walls, the aorta rarely dilates at its orifice sufficiently to put its cusps on the stretch. Unequally-sized cusps when the orifice is stretched must become nnequally deep and so canse their thud of closure asynchronously.

But it might be suggested that the rumble here is really a double nurmur due to regurgitation accompanying a congenital pulmonary stenosis. That is excessively rare. Also the rumble does not in the least resemble a double murnar. Further, the maximum of the diastolic murmur would not be in the second space. And lastly, the second pulmonary sound would require explaining; its accentuation and reduplication make any regurgitation there extremely improbable.

\section{Prognosis.}

Prognosis is the most important point in the case. Patent ductus arteriosus is the one congenital lesion which ever, undergoes spontaneous cure. But that is in early life. Cases which persist into adult life may, however, live to eonsiderable ages; 30 does not appear to be a rery unusual age, and Walsham ${ }^{4}$ has recorded a case which died at 47 , and Hale-White ${ }^{5}$ one which died of angina at 53 with a ductus as large as the anterior tibial artery. Other cases at lesser but considerable ages are mentioned in Abbot's able article in Osler and McCrae's Systcm of Medicine. ${ }^{7}$ Will this patient live so long? The pulmonary artery tends to become atheromatous under the strain, and sometimes begins to leak, as was clinically followed in Thayer's ${ }^{6}$ case, quoted in Laubry and Pezzi's valuable work on congenital heart disease. Here, as has just been said, there is no evidence of regurgitation. ${ }^{8}$ Some die, as in Hale-White's case, of angina, and here anginoid pains are present. The serious feature, indeed, is that disabling symptoms are already in existence. But the conditions of strain of work have been very bad, and his improvement, since he has rested, is considerable. In any form of congenital heart disease one must never forget the curious special liability to infective endocarditis. We can only hope that, with continued rest (seeing that he looks robust), the existing symptoms may subside.

\section{Treatment.}

The treatment has been by rest, at first in bed, now at home, aroiding all strain, good feeding, and, in the way of drugs, small doses of sodium iodide, arsenic, and digitalis, with larger doses of strychnine.

Lastly a word about the effect of change of posture. I have seen four cases of patent ductus. The first was shown by the late Dr. Gibson at a meeting of the Association of Physicians at Edinburgh, when he corroborated the effect I found-namely, that the practically continuous murmur heard in the erect position became definitely discontinuous in recumbency. Another case, seen last May at the London meeting of the same association, showed the same change, which was verified by several present. In the other two cases, this and that of a boy seen in private some rears ago, posture made no change in the duration of the murmur. The point is not merely academic, for in recumbency the murmur, if it is discontinuous, is less distinctive and might be mistaken.

I have to thank my colleague, Dr. Miller Muir, for the trouble he has so kindly taken with the $x$-ray examination, and $m y$ house-physician, Dr. Durrans, for the pulse tracings.

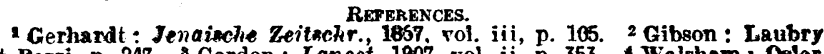
et Pezzi, p. 247. 8 Gordon: Lapcet, 1307, voi. ii, p. 353. A Walsham : Osler and McCrae's System of Medicine, vol. iv, p. 399. 5 Hale-White: Ibid. rol iv, P. Thayer: Laubry et Pezzi, ${ }^{p}$. 218. ' Abbot: Osler and congénitales du cour, Paris, 1921 .

\section{THE MENTAL CONDITION NINE YEARS AFTER MENINGITIS TREATED BY FREQUENT VENTRICULAR PUNCTURE.}

HAZEL, H. CHODAK GREGORY, M.D.,

ASSISTANT PHYSICIAN, ROYAL FREE HOSPITAL, LONDOX.

THE following is an account of the mental condition of a child who was under my care in the Royal Free Hospital in 1917, suffering from a severe attack of meningitis at the age of 5 months. She recovered, and is now 9 years of age.

The onset, with pyrexia, constipation, and fretfulness, was not recognized as that of cerebro-spinal fever until towards the end of the first week, when the tense fontanelle and staring eyes of the first week, when the lense fontanelle and sumbar puncture was then performed suggested the diagnosis. Lumbar puncture was then performed and abundant fluid with large numbers of pus cells and meningococci was obtained. Antimeningococeal serum was given intrathecally and puncture was repeated on the second and fourth days. Unfortunately on the fifth day no fluid could be obtained from the spinal canal, and it became necessary to relieve the tension by puncture of the right lateral ventricle through the lateral angle of the fontanelle. During the next three weeks the intracranial pressure remained very high, and the ventricle was punctured almost every day, yielding sometimes as much as punctured a fuid; this was partly replaced by small doses of $100 \mathrm{c.cm}$. of fluid; this was partly replaced by small doses of antimeningococcal serum. In all $30 \mathrm{c.cm}$. of serum were given. After the first few days meningococci ceased to appear in the ventricular puncture was made at longer intervals, and was stopped at the end of five weeks. By this time a fair degree of hydrocephalus was noticeable, the head measuring $17 \frac{1}{4}$ inches, but the pyrexia and vomiting had ceased and the general condition swelling of the right knee-joint. The infant was sent home in good condition.*

* The case was described in a paper on cerebro-spinal meningitis by Dr. Helen Mackay (Lancet, January, 1920) 